\title{
Development of ODL in a Newly Industrialized Country according to Face-to-Face Contact, ICT, and E-Readiness
}
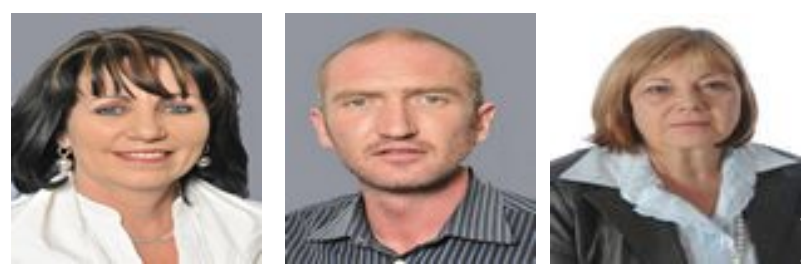

J. Marinda van Zyl, Christoffel Johannes Els, and Anita Seugnet Blignaut North-West University, South Africa

\section{Abstract}

A large number of unqualified and under-qualified in-service teachers are holding back socio-economical development in South Africa, a newly industrialized country. Open and distance learning (ODL) provides an innovative strategy and praxis for developing and newly industrialized countries to reach their educational and socio-economical objectives through professional development and training. In order to examine factors which affect the success of ODL offered by the North-West University in South Africa, a qualitative and quantitative research approach is used. Factors examined include faceto-face classroom contact, the implementation and use of ICTs, and e-readiness. The relationships between these factors are also discussed. A questionnaire was administered to 87 teacher-students in four Advanced Certificate in Education (ACE) programs to collect quantitative data regarding aspects of their classes and the ereadiness of students. This data was qualitatively elaborated upon by three semistructured, open-ended focus-group interviews. Besides descriptive statistics, Spearman's rank-order correlations $(r)$ were determined between variables pertaining to negative feelings towards face-to-face classroom contact, ODL as students' choice of delivery mode, and students' positive attitude towards information and communication technology (ICT). Combined quantitative and qualitative findings were used to evaluate the effectiveness of contact classes as well as the e-readiness of students towards the attainment of ODL development Phase D. This phase refers to UNESCO's description of ICT implementation, integration, and use. Relationships (Spearman's rank-order correlations) between ODL, as teacher-students' choice of educational delivery mode, and aspects of their e-readiness suggest that the e-readiness of teacher-students is 
implicit to their choice of ODL as educational delivery mode for professional development.

Keywords: Open distance learning; ODL; development phases; pedagogical support platforms; contact classes; information and communication technology; ICT; ereadiness; m-learning; mobile learning; South Africa; North-West University

\section{Orientation, Problem, and Aim}

As of 2011, South Africa has been listed as a newly industrialized country (NIC) by the International Monetary Fund (2011). NICs are characterized by (i) an economy that has not yet reached $1^{\text {st }}$ World status but has, in a macroeconomic sense, outpaced it's developing counterparts; (ii) rapid economical growth that is export-oriented; (iii) an increasingly open-market economy that allows free trade; (iv) ongoing industrialization; (v) migration of populations to cities to work in industries, factories, and mines; (vi) increased social freedom and civil rights, and so on (International Monetary Fund, 2011). Albeit this achievement, a large number of unqualified and under-qualified inservice teachers are holding back socio-economical development in the country. In 1994 there were an estimated 85,000 unqualified and under-qualified teachers within the South African Education System, and in 2004 there were still 20,000 unqualified teachers (Pandor, 2004). Since 2005, the Department of Education has released no further statistics in this regard. Distance education (DE) is often the most practical educational mode to deliver professional development to the majority of these teachers who predominantly operate in rural areas. In order for these teachers to enroll full-time at on-campus universities, it is necessary to temporarily halt or abort their teaching responsibilities at already under-staffed schools, which is demographically and financially difficult or impossible (Cilliers, Basson, Kirschner, \& Rutherford, 2000; Pandor, 2004; Van Zyl \& Spamer, 2010). In 2004 the School for Continuing Teachers' Education (SCTE) was established on the Potchefstroom Campus of the North-West University (NWU) in order to deliver a constructive contribution to improved education in South Africa. Since 2005, SCTE has provided training and professional development via open distance learning (ODL) to unqualified and under-qualified in-service teachers, who predominantly work in rural areas.

Edwards (1995) and Picciano (2000) promote open distance learning (ODL) as a new educational delivery mode that diverges from DE. DE makes teaching over distance possible to a mass market through the use of curricula and mass-produced course materials that are lecturer-centered. ODL, on the other hand, is student-centered, focusing on the individual needs and expectations of students and local requirements, rather than delivering pre-pact curricula for the masses (Edwards, 1995; Picciano, 2000). According to Moore and Kearsley (2004), ODL has unique characteristics: Students can enroll for a course or program if they meet the required enrolment criteria, 
and students can start with a course or program at any location or time of the year. Students may be able to design their own unique curriculum to meet specified credits. According to the United Nations Educational Scientific and Cultural Organization (UNESCO, 2002), there is a growing interest in ODL, usually supported by the implementation and use of various forms of information and communication technology (ICT).

The implementation and use of ICT in education refers to the implementation and use of various types of technology (i.e., both hardware and software), including the Internet, to transmit knowledge, particularly to students who are not already highly motivated to learn or well versed in the art of using and interpreting information (Carnoy, 2004). UNESCO (2002) describes the development of DE and ODL according to four phases of ICT implementation, integration, and use (Table 1). In ODL, the use of ICT makes the transference of knowledge and skills possible to large numbers of students, regardless of space and time (Keegan, 1996; Moore \& Kearsley, 2004).

Table 1

UNESCO Development Phases of DE and ODL according to ICT Implementation, Integration, and Use

Development

phases of DE ICT implementation, integration, and use

and ODL

Phase A

Correspondence systems based on written and printed documents, often accompanied by audio-visual material that is send via postal service

Phase B Educational television and radio systems that use a variety of innovative technology for teaching and learning communication, e.g., landlines, satellite and cable TV and the broadcasting of direct or prepared lectures to individual home-based students or student groups in distant classrooms

Phase C Multimedia systems that include text, audio, video, and computerbased materials, as well as personal contact to groups and individuals to certain extend. Specialist teams are involved in the presentation and distribution of programs to a large number of students who are often spread over an entire country 
Development

phases of DE ICT implementation, integration, and use and ODL

Phase D

\begin{abstract}
Internet-based systems through which multimedia materials (text, video and graphics) are delivered through computers to individual students in electronic format, as well as access to data-bases and electronic information systems (libraries). Also, creates space for contact classes and vacation schools in which lecturers/facilitators support and provide students with study guidance
\end{abstract}

E-learning refers to the use of electronic technology (i.e., ICT) to deliver educational material and learning (Law, Pelgrum, \& Plomp, 2008). Rosenberg (2001) limits elearning to the use of Internet technology to enhance the learning and outcomes of students. Web-based learning is increasingly being used to deliver essential practical skills training as more applications, such as specialized software simulations for scientific laboratory experiments, become available and are being integrated and used by ODL institutions as part of their e-learning. E-readiness refers to students' readiness to make use of ICT and e-learning within their studies (Du Toit, 2010), including how to access, evaluate, and adapt resources for teaching and learning, establishing a blog or Web site, and so on. Since 2005, the SCTE has implemented various ICT innovations in support of curriculum outcomes and contact classes, including television broadcasts, short message services (SMSs), educational digital video discs (DVDs), as well as Internet access and interactive whiteboards at study centers. Some, such as television broadcasts, were found to be impractical and not financially viable.

NWU (SCTE) undertook various international audits to evaluate and ensure the quality of the academic programs it offers; however, it became essential to evaluate various components that influence the overall development and success of the ODL delivery mode being used at the institution. According to Peters (2000), Tait (2000), and Zheng and Smaldino (2003), the development and success of DE and ODL are determined by various components: (i) curriculum and interactive study material specifically developed for the unique context of DE and ODL students, recognizing their unique educational needs and expectations, barriers, and socio-economical context; (ii) an academic contract, explicit or implicit, between lecturers and students to work towards the achievement of specific learning outcomes; (iii) an effective two-way communication network between lecturers and students; (iv) face-to-face classroom contact; (v) the implementation, integration, and use of various types of ICT; (vi) student e-readiness; (vii) effective logistics; (viii) continuous research and reflection; (ix) delivery mechanism; (x) frequency of feedback; (xi) testing; (xii) interactivity, and so on. 
According to Guri-Rosenblit (2005), many DE/ODL programs make use of additional face-to-face classroom/tutorial contact during vacations (e.g., summer schools). Note also that face-to-face contact classes contribute to the success of ODL because they deliver important additional pedagogical support to ODL students as contact classes provide an opportunity to interact with and receive support from lecturers/facilitators and other students (Garrison \& Vaughan, 2008). Attendance at face-to-face classroom contact is usually non-compulsory because of its pedagogical supportive function. The SCTE (NWU) presents additional, non-compulsory face-to-face classroom contact over weekends and during school holidays within a radius of $100 \mathrm{~km}$ from each student's home/workplace. During these face-to-face tutorials of approximately one hour per module, lecturers and facilitators review difficult and important module content, while students are assisted with their problems and have the opportunity to network with each other. Students are encouraged to form study groups.

Previous impact research conducted by the NWU on its ACE-programs delivered via ODL (e.g., Kok, Rabe, Swarts, Van der Vyver and Van der Walt, 2010) found that students are satisfied with the quality of module content. The current investigation found that $93.2 \%$ of students who attended face-to-face classroom contact and $88.4 \%$ of those students who did not attend any contact classes reported that they are satisfied with module content and the study material they received.

The scope of the current investigation entails specifically the fourth, fifth, and sixth components listed above by formulating the following research aim: to evaluate the development and success of ODL, as the educational delivery mode used by the SCTE at NWU within the context of a newly industrialized country, according to face-to-face classroom contact, the implementation and use of ICT, and the e-readiness of students.

\section{Research Design and Methodology}

This investigation used a sequential developing research design (Leech \& Onwuegbuzie, 2009; Onwuegbuzie \& Leech, 2005) that made use of mixed-methods which included both quantitative and qualitative research methods for data collection and analysis (Onwuegbuzie \& Leech, 2005; Tashakkori \& Teddlie, 2003).

\section{Quantitative and Qualitative Sampling}

The study sample is representative of the students registered in four Advanced Certificate in Education (ACE) programs (i.e., Foundation Phase, Learner Support, Mathematics Education, and Geography). These programs were delivered by the SCTE via ODL to students throughout the nine provinces of South Africa. A computer-based random selection was performed to identify 200 students. Of these students, 100 attended one or more contact sessions at one of the 29 study centers throughout South Africa during February, March, May, August, and September 2009, and 100 students 
attended no contact sessions during this period. The 200 students were selected from an initial pool of 1,310 students who wrote the ACE examination during October 2009. Of the 200 students who were invited to voluntarily participate, 87 students participated in the study. Forty-four of these students attended no contact classes and 43 attended one or more contact classes. Table 2 provides the demographical information of the students involved in the quantitative research sample.

Table 2

Demographical Information of the Quantitative Sample ( $\mathrm{N}=87)$

\begin{tabular}{|c|c|c|c|c|c|c|}
\hline & \multicolumn{2}{|c|}{$\begin{array}{c}\text { Attended no contact } \\
\text { classes }\end{array}$} & \multicolumn{2}{|c|}{$\begin{array}{l}\text { Attended one or more } \\
\text { contact classes }\end{array}$} & \multicolumn{2}{|c|}{ Totals } \\
\hline & $\mathrm{n}$ & $\%$ & $\mathrm{n}$ & $\%$ & $\mathrm{n}$ & $\%$ \\
\hline \multicolumn{7}{|l|}{ ACE programs } \\
\hline Mathematics Education & 12 & 27.3 & 7 & 16.3 & 19 & 21.8 \\
\hline Learner Support & 17 & 38.6 & 19 & 44.2 & 36 & 41.4 \\
\hline Foundation Phase & 14 & 31.8 & 16 & 37.2 & 30 & 34.5 \\
\hline Geography & 1 & 2.3 & 1 & 2.3 & 2 & 2.3 \\
\hline Total & 44 & 100 & 43 & 100 & 87 & 100 \\
\hline \multicolumn{7}{|l|}{ Gender groups } \\
\hline Female & 33 & 75 & 36 & 83.7 & 69 & 79.3 \\
\hline Male & 11 & 25 & 7 & 16.3 & 18 & 20.7 \\
\hline Total & 44 & 100 & 43 & 100 & 87 & 100 \\
\hline \multicolumn{7}{|l|}{ Age groups } \\
\hline $31-40$ & 17 & 38.6 & 12 & 28.6 & 29 & 33.7 \\
\hline $41-50$ & 23 & 52.3 & 24 & 57.1 & 47 & 54.6 \\
\hline $51-60$ & 4 & 9.1 & 5 & 11.9 & 9 & 10.5 \\
\hline 61 and older & - & - & 1 & 2.4 & 1 & 1.2 \\
\hline
\end{tabular}


Regions (provinces)

$\begin{array}{lcccccc}\text { Eastern Cape } & 8 & 18.2 & 13 & 30.2 & 21 & 24.1 \\ \text { Free State } & 1 & 2.3 & 1 & 2.3 & 2 & 2.3 \\ \text { Gauteng } & 2 & 4.5 & - & - & 2 & 2.3 \\ \text { KwaZulu-Natal } & 5 & 11.4 & 4 & 9.3 & 9 & 10.3 \\ \text { Limpopo } & 5 & 11.4 & 9 & 20.9 & 14 & 16.1 \\ \text { Mpumalanga } & 6 & 13.6 & 7 & 16.3 & 13 & 14.9 \\ \text { North-West } & 8 & 18.2 & - & - & 8 & 9.2 \\ \text { Northern Cape } & 3 & 6.8 & 3 & 7.0 & 6 & 6.9 \\ \text { Western Cape } & 6 & 13.6 & 6 & 14.0 & 12 & 13.8 \\ \text { Total } & 44 & 100 & 43 & 100 & 87 & 100\end{array}$

In order to collect in-depth context sensitive data regarding student experiences, expectations, needs, and fears concerning face-to-face classroom contact, the implementation and use of ICT, as well as their e-readiness, three groups of students comprising eight students per group were selected to participate in qualitative focusgroup interviews. Members of these focus groups were representative of the four ACE programs and of both gender groups. Approximately 50\% of those in focus groups attended one or more contact classes and 50\% attended no contact classes.

\section{Mixed-Methods Data Collection}

Data was collected using quantitative and qualitative data collection methods and procedures. A five-point Likert-type questionnaire (scales: totally agree, agree, do not know, disagree, and totally disagree) was designed by the researchers. The questionnaire design and items were evaluated and approved by the Department of Statistical Consultation Services at NWU. The questionnaire comprised a demographical section, followed by 49 items regarding various aspects of contact classes, including quality, perceived value, and problems experienced. The questionnaire also included a section on the e-readiness of students (16 items). Besides 
the Likert-type items, the quantitative questionnaire also included open semi-structured questions that collected qualitative data in the form of written responses (personal narratives) regarding the opinions and experiences of students regarding contact classes. The questionnaire was mailed, together with a self-addressed pre-paid envelope, to the respondents. A research letter that accompanied the survey described the nature and objectives of the study as well as an invitation to voluntarily and anonymously participate. No time limit was prescribed to complete the questionnaire. As very few participants have access to fax machines (which are very expensive in South Africa) they were not asked to fax the questionnaires back. Participants were asked to mail their completed questionnaires back to the researchers using the self-addressed pre-paid envelope. The slowness and efficiency of the mail system were taken into account and could have been contributing factors for the return rate of $43.5 \%$ ( $\mathrm{N}=$ 87/200). The identities of research participants were unknown to the researchers as the questionnaire did not collect any data that could identify participants. A Microsoft Office Excel ${ }^{\mathrm{TM}}$ file captured the data for analysis.

The qualitative focus-group interviews were guided by a semi-structured open-ended series of questions. Students were contacted by telephone and invited to voluntarily and anonymously participate at two contact centers on pre-arranged dates. Two interviews were conducted at the Potchefstroom study centre, another at the Rustenburg study centre. Students completed permission and consent forms. Interviews were captured with digital data-recorders and transcribed by the researchers. Qualitative data collected by the questionnaire (personal hand-written narratives) was combined with focus-group interview data into an integrated qualitative dataset. The textual responses and interview transcriptions were captured in a Microsoft Word ${ }^{\mathrm{TM}}$ file for qualitative dataanalysis.

\section{Data Analysis}

A professional statistician from the Department of Statistical Consultation Services (NWU) used Statistical Package for the Social Sciences $\left(\right.$ SPSS $^{\mathrm{TM}}$ ) to perform the quantitative data-analysis. Although distinction was made between students who attended one or more contact sessions and those who did not, from the findings it became clear that those students who did not attend any contact classes answered the questions pertaining to contact class attendance as if they did attend. These students most likely attended contact classes in the past (before February 2009). Besides descriptive statistics, Spearman's rank-order correlations ( $r$ ) were determined between variables (items) on the five-point Likert scale of the questionnaire as these items exhibit rank-order. Spearman's rank-order correlations (r) are interpreted as follows: $r=0.1$ (small effect); $r=0.3$ (statistical medium effect that tends towards a practical significance) and $r \geq 0.5$ (a large effect indicative of practically significant correlations).

One of the researchers used Atlas.ti ${ }^{\mathrm{TM}}$ to analyze the integrated dataset according to the constant comparative method of content analysis (Glaser, 1965), which identified data 
categories and themes relating to students' perceptions, experiences, problems, challenges, and expectations concerning contact classes, as well as their e-readiness. Coding density of data categories relevant to the current exposition are (i) positive perceptions and experiences of students concerning contact classes-four themes, 159 quotations; (ii) challenges and barriers that prevent students from attending contact classes-five themes, 82 quotations; (iii) problems, negative opinions, and experiences of contact classes-two themes, 66 quotations; (iv) computer literacy-62 quotations; (v) access to technology-21 quotations; (vi) learning with technology-26 quotations; (vii) DVDs-9 quotations; and (viii) mobile learning-5 quotations. Codes, categories, and themes reduced the data to highlight the key issues.

\section{Discussion of Findings}

Both quantitative and qualitative findings are integrally reported through the trifocals (i) effective face-to-face classroom contact, (ii) the implementation and use of ICT, and (iii) the e-readiness of students.

\section{Effective Face-to-Face Classroom Contact}

Since 2005, the SCTE has used an ODL delivery mode that integrates face-to-face classroom contact/tutorials. Teacher-students have the opportunity to attend scheduled non-compulsory classroom contact (twice a month and mostly over weekends and during school vacations) at any of the 29 study centers. Mixed-methods identified the following findings pertaining to face-to-face classroom contact.

\section{Satisfaction with geographical location of contact centers.}

The majority of students (89.5\%; 77/ 86) who answered the questionnaire (i.e., 95.3\% of students who attended contact classes and $83.8 \%$ who did not) indicated that they are satisfied with the geographical locations of contact classes. However, despite the fact that all students have contact centers located within a radius of $100 \mathrm{~km}$, geographical distances seem to remain a challenge for some students who participated in the focusgroup interviews, mainly due to travelling costs.

\section{Satisfaction with the quality of face-to-face classroom contact.}

In general, $65.6 \%$ (40/61) of students reported that they are satisfied with the quality of face-to-face classroom contact. Of the total group of students who attended no contact classes, $31.7 \%$ are not satisfied with the quality of contact classes. The qualitative interview data reveals the following factors that possibly contribute to students' dissatisfaction with the quality of face-to-face tutorials: (i) scheduling of classroom contact, (ii) low quality of certain lecturers/facilitators, (iii) advancement of certain students, (iv) language of instruction, and (v) bad relationships with certain 
lecturers/facilitators. Students' dissatisfaction with the quality of face-to-face classroom tutorials contributes to students' negative feelings. From this finding one could speculate that students' dissatisfaction with the quality of contact classes may be a possible reason for non-attendance.

\section{Reasons for face-to-face classroom attendance (motivation and perceived value).}

Qualitative findings reveal that students' main motivation for contact class attendance involves the information they receive as well as the opportunity to ask questions to lecturers/ facilitators:

During contact classes I feel positive because I get all the information in my modules and also how to study them and how to do some of my assignment that I was not aware of. I also get the previous questioning styles in each module.

I feel positive because I get more explanation. I also have a chance to ask questions when I don't understand.

Accordingly, the majority of students' value face-to-face classroom contact/tutorials because of the contact they have with lecturers/facilitators and the personal study guidance they receive from them:

Contact sessions are of the utmost importance because the lecturers explain all the modules...then students do understand the assignments and the exam.

...but my experience from the contact sessions...I sat in one contact session where I was the only student, and it was fantastic, I got special treatment it was a very wonderful contact session, as it was the one that I really needed, it was computers. I was very pleased.

In response to the questionnaire, 90.6\% (77/ 85) of students indicated that they attend contact classes to ask study-content questions to lecturers/facilitators; while $75.8 \%$ (47/62) specified that contact classes help them complete assignments. While $86.9 \%$ (73/84) of students reported that contact classes help them to prepare for examinations, $81.3 \%$ of those who attended, and $70.7 \%$ of those who did not, pointed out that they would not merely attend contact classes to receive examination information or tips. Of the total group of students who attended one or more contact classes, $62.8 \%$ indicated that they received individual attention at contact classes during 2009. 
Students furthermore reported in the focus-group interviews that they attend contact classes to obtain additional information from lecturers/facilitators: "We attend to get information...And we go because we don't have anybody else who can help us."

This seems to have a positive effect on the self-confidence of students: "I felt more confident with the contact sessions."

The overall findings indicate that $79 \%$ of students who attended contact classes and $85.7 \%$ of students who did not, believe that to study via ODL is the best for students like themselves; while $92.9 \%$ of both groups indicated that the NWU must continue to deliver programs via ODL.

\section{Reasons for no contact class attendance (barriers).}

The majority of students ( $74.4 \%$ of students who attended contact classes and $72.1 \%$ who did not) indicated that personal circumstances prevent them from attending contact classes. Students reported during the interviews that distances to contact classes, financial barriers, and personal responsibilities (e.g., family obligations) were the main challenges preventing them from attending contact classes. These reasons validate why face-to-face classroom contacts should not be compulsory.

The only challenge is that the centre is very far from where I live.

What I dislike: contact sessions are too expensive for me because I am travelling from one place to another paying a lot of money for transport and food.

I feel positive-it is just that I cannot attend regularly due to financial problems, and the distance.

Some individuals are parents with matrics or tertiary students as children which brings along vital primary responsibilities.

It seems that financial barriers are not predominantly the cause for no contact class attendance as $53.4 \%$ of students who attended contact classes, and $55.8 \%$ of those who did not, indicated that it is not too expensive for them to attend contact classes.

Factors like personal circumstances and responsibilities (74.1\%), financial barriers, large distances to contact classes, and circumstances beyond their control seem to be the major reasons that prevent teacher-students attending contact classes. These and other factors are the reasons why face-to-face classroom contact is non-compulsory for NWU ODL students. 
Strangely enough, $58.1 \%$ of students who attended face-to-face classroom contact, and $43.9 \%$ of those who did not, were of the opinion that students should not have the right to decide for themselves whether or not to attend contact classes. Some students possibly feel that they will attend contact classes if they are forced to do so.

\section{Negative attitude (feelings) towards face-to-face classroom contact/tutorials.}

As already noted, $34.4 \%$ (21/61) of students are dissatisfied with the quality of face-toface classroom contact. Despite student dissatisfaction, $93.1 \%$ of the total sample of teacher-students experience face-to-face classroom contact positively, while $5.7 \%$ experience it negatively. In order to help clarify the underlying reasons for students' negative attitudes, Spearman's rank-order correlations ( $r$ ) were calculated. Practically significant correlations ( $r=0.8$ ) were calculated between negative feelings towards face-to-face classroom contact and (i) not being satisfied with the quality of contact classes, (ii) not being satisfied with facilitators' presentation of contact classes, and (iii) not being satisfied with guidance received from facilitators. These correlations show some of the underlying reasons why $5.7 \%$ of the total sample $(\mathrm{N}=87)$ experiences contact classes negatively. As these Spearman rank order correlations were calculated for a very small sample ( $5.7 \%$ of 87 ), they should not be generalized.

Students' negative perceptions and experiences concerning various aspects of contact classes were further revealed by the findings of the qualitative research component. Students have a problem with contact classes scheduled on Friday afternoons after school hours as they have responsibilities at their schools that prevent them from attending. Furthermore, time available between various contact classes seems to be a problem:

The gap between my modules for example when my 1st module is 9:00 (course name) the 2nd is 12:00 (course name) and the 3rd is 15:00 now I have to wait for a long time and feel bored because my modules are so far.

Other students feel that too many modules are presented at a specific contact class session, and that not enough time is allocated for each module to go over important content and discuss problems: "The things that I dislike are that there is no enough time for modules."

\section{Implementation and Use of ICT}

As already pointed out, UNESCO (2002) describes the development of ODL according to four phases of ICT implementation and use (Table 1). The SCTE went through the first three development phases (Phases A-C on Table 1). Instead of focusing on the development of Internet-based systems in Phase D, the SCTE's teaching-focus shifted more to personal contact (contact classes) mainly as a result of students' low computer 
and Internet access in rural areas (Blignaut \& Els, 2009; Law, et al., 2008). Although SCTE installed computers with free Internet at study centers and there is a constant increase in computer ownership and use among students, lack of ICT knowledge and skills still hampers the potential realization of e-learning.

\section{E-Readiness of Students}

SCTE has also recently initiated m-learning and a web-based Moodle platform for pedagogical support, with free Internet access and mini-libraries available to teacherstudents at 36 study centers. The following findings pertaining to the e-readiness of students is provided below.

\section{Access to computers and the Internet.}

Of the total number of students who attended contact classes, $46.5 \%$ have access to a computer at home, against 53.5\% who do not. Only 29.5\% of students who did not attend any contact classes have computer access at home, while $70.5 \%$ of them do not. Students who do not have computer access at home also tend not to attend any contact sessions. Of the total sample, 73.6\% (64/87) have access to a computer at school/ work. Correspondingly, some students confirmed access to computers at home/ school during the focus-group interviews, while others indicated the absence of technology access and skills:

The thing is, there are less computers in our schools that is why most of us are still behind with this technology of computer, because there are few and it is used with administration. You see, so if you are not in the administration it is very difficult for you unless you got your own one.

So and then the problem is that not all of us are having this computers at our homes, and then not all of us can operate it.

Only 9.3\% (8/86) of students have access to the Internet at home, while $29.9 \%$ (26/87) have Internet access at school/work. The latter finding possibly reflects the phenomena, reported by Els and Blignaut (2009), that at most schools, especially at those in rural areas, the Internet is exclusively being used by school management and administration.

\section{Computer literacy.}

Twenty of 43 students (46.5\%) who attended face-to-face classroom contact and 13 of 44 of those who did not attend (29.5\%) indicated that they own a computer at home. The qualitative data reveals that some students are not computer literate, while others 
indicated that it is a priority for them to attain computer literacy and that they do not fear this challenge:

Technology is very important for us [in] the future, we cannot get away from that...Technology is important for whatever you need to do as a person...to type a document or to search for things on the Internet

We feel overwhelmed...we feel pleased. I am not afraid of technology, because..in so many, many ways, people are..trying..to talk with me, with CDs, DVDs, whatever...

And computer literacy promotes their self-confidence: "But going through that course that I was supposed to do, it was such a learning curve.. and at the end of it I felt much more confident, and I was able to adjust those assignments."

Providing they receive support and guidance, computer illiterate students tended to be optimistic about their future use of computers: "But I think if someone could show me how to do it, it would help.. I will be able to do that. . I would be prepared to do that."

While some students indicated that their circumstances forced them to become computer literate, others emphasize the role of socio-economical and geographical contexts for the absence of computer literacy:

That is another issue, you know, from where I am working. . it is a little bit of a farm school. I really want to type it so that it would look very nice for the lecturer.. so that the lecturer will see this guy tried his best. Then I write it, but sometimes I would turn to someone and ask, will you type it please? But this cost money... It is a problem.

\section{Learning with technology.}

Surprisingly, 70.9\% (61/86) of students feel comfortable to use computers, while 65.5\% reported they find it easy to type assignments on a computer. The former finding is possibly an indication of students positive attitude towards computers and their future prospects of using computers, while the latter finding could indicate that either it is possible for students to type their assignments themselves or that it is possible for them to let their assignments be typed by someone else. Some students confirmed during interviews that they type assignments on personal computers:

Yes, I do have my own computer at home. 
I did type mine, I just want to say computers are very much helpful to our lives, because it save more time, and it is neat if you use a computer. Especially for myself, my handwriting's so bad. At least now I have submitted something that is nice. Anyone which can take it, can read it what I've wrote there.

Only 40.7\% (35/86) of students feel comfortable to use the Internet, while 64\% (55/86) are capable of getting information from the NWU (SCTE) Web site. It can be speculated that more students make use of the Internet, with support from others, than students who use the Internet by themselves. While $45.9 \%$ (39/85) of students feel that the SCTE should make more use of the Internet and emails to send information to students, only 34.9\% (30/ 86) feel that the SCTE should make more use of the Internet and emails to send study material to students. Only $32.3 \%(20 / 62)$ of students find it easy to submit their assignments via email. The majority of students ( $76.2 \%$ who attended one or more contact classes and $84.1 \%$ who did not attend any) do not use email. Overall, students emphasized the importance of technology for learning: "Technology is very important for us the future, we cannot get away from that."

\section{Mobile learning (m-learning).}

The majority of students (78/86; 89.7\%) have their own mobile phones. Despite the fact that mobile-learning is restricted by students who own old mobile phone models that lack certain functions (e.g., to receive multimedia messaging services or MMSs) (37.9\% in the current investigation), 62.1\% (54/87) already own mobile phones that receive photos and MMSs. Students seem interested in m-learning:

I use my cellphone, especially when I'm doing my assignments.

I think the technology is more important, especially to get the information from the cellphones, and also we get information from the cellphone and the computer. So it saves our time.

Currently, study information is sent to students' mobile phones, while some students, on their own or assisted by others, use their mobile Internet connection to access relevant study information from the NWU Web site. Of the total sample, 93.1\% (81/87) indicated that the SCTE should make more use of mobile communication to send information to students, while 93.1\% (81/87) feel mobile phones should be used to communicate timetables to students. Considering that the SCTE already makes use of short message services (SMS) to remind students of contact classes, 96.6\% (84/87) of students confirmed that they regularly receive SMSs concerning contact classes. This 
finding supports the findings of Turtiainen et al. (2009) that m-learning has an increasingly important role to play in developing and newly industrialized contexts.

\section{Educational DVDs.}

During the focus-group interviews, some students praised the educational DVDs that they receive and encouraged the SCTE to make more use of this type of ICT, while others felt that the DVDs were superficial and did not provide sufficient information:

That is way I'm saying I found them a bit superficial, they were not sufficient, there were not enough meat on them. Once I got them, I have to be honest; I never put them on again. I felt that I got more out of the books and the discussions with the lecturers. And also from extra reading.

\section{Relationship between ODL, as Students' Choice of Educational Delivery Mode, and Aspects of E-Readiness}

Meaningful relationships (correlations) were found between variables on the questionnaire, using Spearman's rank order correlations. Figure 1 shows how ODL, as students' choice of educational delivery mode, relates to aspects of their e-readiness by means of the combined Spearman's rank-order correlation results. 


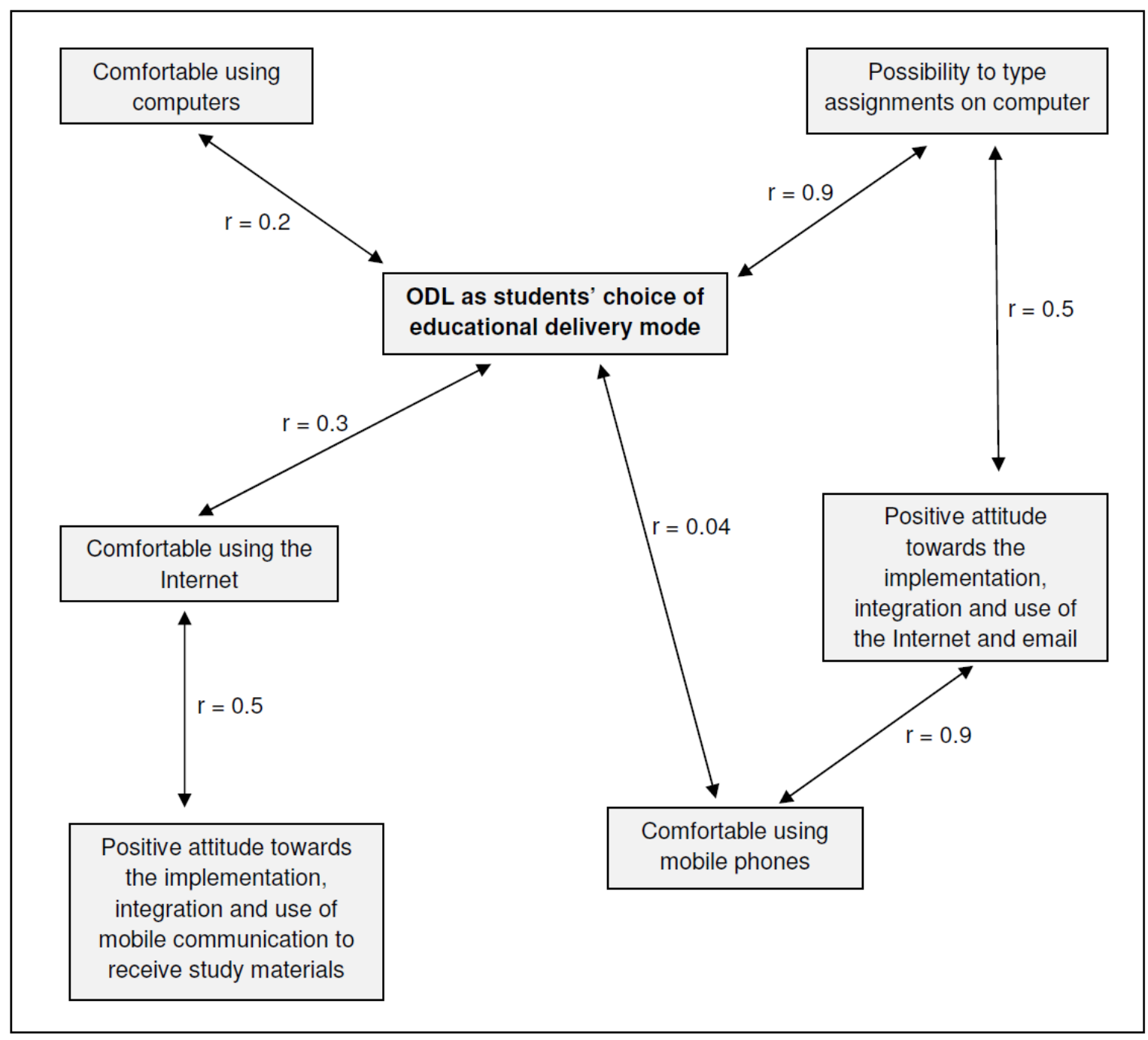

Figure 1. Relationships (Spearman's rank-order correlations) between ODL, as students' choice of educational delivery mode, and aspects of their e-readiness.

As illustrated in Figure 1, a very strong relationship ( $r=0.9$ ) was found between ODL, as students' first choice of educational delivery mode, and the possibility for students to type assignments on a computer. The latter capability relates to a large extent $(r=0.5)$ to a positive attitude towards the implementation and use of the Internet and email to receive study materials, which has a very strong relationship $(r=0.9)$ to being comfortable using mobile phones. These results, pertaining to the current group of students who choose ODL as educational delivery mode, indicate that most ODL students consider it possible to type an assignment on computer, whether by themselves or through the assistance or service of others. Furthermore, these students have a predominately positive attitude towards the implementation and use of the Internet and email to receive study materials and feel very comfortable using mobile phones. ODL, 
as students' choice of educational delivery mode, also relates to a medium extent ( $\mathrm{r}=$ 0.3 ) with being comfortable using the Internet, which, in turn, strongly relates ( $r=0.5)$ to a positive attitude towards the implementation, integration, and use of mobile communication to receive study materials (m-learning). These results indicate that most students who feel positive and comfortable using the Internet (currently or in the future) choose ODL as educational delivery mode. Furthermore, these students have a positive attitude towards the implementation, integration, and use of mobile communication to receive study materials.

Interpreted as a whole, these findings suggest that the e-readiness of teacher-students is implicit to their choice of ODL as educational delivery mode for their professional development.

\section{Recommendations}

Based on the findings of this report, the SCTE (NWU) could improve its ODL offerings in the following ways.

\section{Effective Face-to-Face Classroom Contact}

Although the overall findings indicate that most students are satisfied with the quality of face-to-face classroom contact (65.6\%) and perceive additional non-compulsory classroom contact as valuable pedagogical support (96.5\%), it is recommended that the SCTE investigates how to increase student satisfaction with contact classes in general. It is furthermore recommended that the SCTE investigate how to improve the quality of facilitators' presentations and guidance. Students also reported qualitatively that the scheduling of face-to-face classroom contact on Friday afternoons (after school hours) is difficult for them as they have responsibilities at their schools that prevent them from attending. Further, the time available between various contact classes is a problem. These negative experiences of students should be taken into account, within reasonable context and practicality, for future timetable planning.

\section{Implementation, Integration, and Use of ICT}

With regard to the implementation, integration, and use of ICT, the ODL delivery mode of the SCTE attained the first three development phases (Phases A-C) described by UNESCO (2002), as outlined in Table 3. In Phase D, instead of implementing, integrating, and using Internet-based systems through which multimedia materials (text, video, and graphics) are delivered through computers, the ODL delivery mode of the SCTE shifted its focus more to personal contact (contact classes), with computer and Internet access at study centers throughout all provinces. The constant increase in teacher-students' access to computers and the Internet, their attainment of computer literacy as part of their continuous professional development, and, subsequently, their 
e-readiness unlock the opportunity for the ODL delivery mode of the SCTE to fully implement and achieve Phase D development.

\section{Teacher-Students' E-Readiness}

Interpreted as a whole, the findings in Figure 1 suggest that the e-readiness of teacherstudents is implicit to their choice of ODL as the educational delivery mode for their professional development. Considering the fact that some students still do not have access to computers and the Internet and some lack the necessary computer literacy and general ICT skills, it is highly recommended that the SCTE initiate Internet-based elearning. Within the specific ODL context of the NWU, e-learning should be implemented as a non-compulsory educational mode for the growing number of students who are already e-ready. Furthermore, the NWU should increasingly implement, integrate, and make use of m-learning, while continuing with already established face-to-face contact classes, using both printed paper-based study material and various ICT to deliver quality ODL programs.

This research was specifically conducted within the socio-economical context of a newly industrialized economy. Accordingly, the findings not only contribute to ODL scholarship in newly industrialized economies, but also indicate to developing contexts what to expect. Developed contexts, on the other hand, could compare the findings with their own contexts to explore the impact of development. 


\section{References}

Blignaut, S., \& Els, C. J. (2009, J une). The hare and the tortoise: a comparison of Northern and Southern hemisphere findings of the SITES 2006. Paper presented at the IADIS Multi Conference on Computer Science and Information Systems, Algarve, Portugal.

Carnoy, M. (2004). ICT in education: Possibilities and challenges. Barcelona: Universitat Oberta de Catalunya.

Cilliers, J . A., Basson, I., Kirschner, P. A., \& Rutherford, M. (2000). Current views of the purpose of the introductory physics laboratory in South Africa: Part II specific objectives. South African J ournal of Higher Education, 14(1), 20-30.

Du Toit, C. (2010). Riglyne vir effektiewe onderwys in afkampusonderwysprogramme vir praktiserende onderwysers (Unpublished $\mathrm{PhD}$ thesis) Faculty of Education Sciences, North-West University, Potchefstroom.

Edwards, R. (1995). Different discourses, discourses of difference: Globalisation, distance education and open learning. Distance Education, 16(2), 241-255.

Els, C. J., \& Blignaut, A. S. (2009, Sept.). Qualitative case studies of context sensitive ICT pedagogical practices of teachers in the North-West province. Paper presented at the 11th Annual Conference on World Wide Web Applications, Port-Elizabeth.

Garrison, D. R., \& Vaughan, N. D. (2008). Blended learning in higher education: Framework, principles and guideline. San Francisco: J ossey-Bass.

Glaser, B. G. (1965). The constant comparative method of qualitative analysis. Social Problems, 12(4), 445.

Guri-Rosenblit, S. (2005). Distance education' and 'e-learning': Not the same thing. Higher Education, 49(4), 467-493.

International Monetary Fund. (2011). World economic outlook (WEO) report - tensions from the two-speed recovery: Unemployment, commodities and capital flows. Washington: International Monetary Fund.

Keegan, D. (1996). The foundations of distance education. New York: Routledge.

Kok, I., Rabe, A., Swarts, P., Van der Vyver, C., \& Van der Walt, J. L. (2010). The effectiveness of a course for helping educators cope with the demands of the IQMS. African Education Review, 7(2), 342-355. 
Law, N., Pelgrum, W. J., \& Plomp, T. (Eds.). (2008). Pedagogy and ICT use in schools around the world: Findings from the IEA SITES 2006 study. Hong Kong: Springer.

Leech, N. L., \& Onwuegbuzie, A. J. (2009). A typology of mixed methods research designs. Quality \& Quantity: International J ournal of Methodology, 43, 265275.

Moore, M. G., \& Kearsley, G. (2004). Distance education: A systems view. Belmont: Wadsworth Publishing Company.

Onwuegbuzie, J., \& Leech, N. L. (2005). On becoming a pragmatic researcher: The importance of combining quantitative and qualitative research methodologies. International J ournal of Social Research Methodology, 8(5), 375-387.

Pandor, N. (2004). Promoting quality in state schools (Speech delivered by former Minister of Education at the Boys Only Principal Conference, 25 August 2004, Rondebosch). Retrieved from http:// www.info.gov.za/ speeches/2004/04083013451002.htm

Picciano, G. (2000). Distance learning: Making connections across virtual space and time. Upper Saddle: Merrill Prentice Hall.

Rosenberg, M. (2001). E-Learning: Strategies for delivering knowledge in the digital age. Educational Technology \& Society, 6(3), 80-81.

Tashakkori, A., \& Teddlie, C. (2003). Handbook of mixed method research in the social and behavioral sciences. Thousand Oaks: Sage.

Turtiainen, E., Blignaut, A. S., Els, C. J ., Laine, T. H., \& Sutinen, E. (2009). Story-based UFractions mobile game in South Africa: Contextualization process and multidimensional playing experiences. Paper presented at the 2nd International Workshop on Story-Telling and Educational Games (STES'09) by die 8th International Conference on Web-based Learning 2009, Aachen University, Aachen, Germany.

United Nations Educational Scientific and Cultural Organization. (2002). Open and distance learning: Trends, policy and strategy considerations Retrieved from http:// unesdoc.unesco.org/ images/ 0012/001284/ 128463e.pdf

Van Zyl, M. J., \& Spamer, E. J. (2010). Distance education programmes for the upgrading of teachers' qualifications in South Africa: The effect of contact class attendance on pass rates. Paper presented at the Hawaii International Conference on Education, Honolulu, Hawaii. 


\section{Athabasca University $\mathbf{I}$}

(c) (†) 